Original Research Paper

\title{
Hepatoprotective Effect of Opuntia Ficus-Indica Aqueous Extract against Carbon Tetrachloride-Induced Toxicity in Rats
}

\author{
${ }^{1,2}$ Zouhir Djerrou, ${ }^{2}$ Zineb Maameri, ${ }^{2}$ Sihem Halmi, ${ }^{2}$ Hadria Djaalab, \\ ${ }^{2}$ Foulla Riachi, ${ }^{2}$ Loubna Benmaiza and ${ }^{2,3}$ Youcef Hamdipacha \\ ${ }^{1}$ Department of Sciences of Nature and Life, Faculty of Sciences, University of August 20 ${ }^{\text {th }}$ 1955, Skikda, Algeria \\ ${ }^{2}$ Laboratory of Pharmacology and Toxicology, Institute of Veterinary Sciences, University of Mentouri Constantine, Algeria \\ ${ }^{3}$ Head of High National Veterinary School, El Harrach, Algeria
}

Article history

Received: 28-03-2015

Revised: 03-04-2015

Accepted: 30-05-2015

Corresponding Author:

Zouhir Djerrou

Department of Sciences of

Nature and Life, Faculty of

Sciences, University of August

$20^{\text {th }} 1955$, Skikda, Algeria

Email: zouhir21265@yahoo.fr

\begin{abstract}
The present study was undertaken to evaluate the hepatoprotective activity of Opuntia ficus-indicaL. aqueous extract. About 24 Wistar male rats were divided randomly to 4 groups of 6 each. The 1st was given distilled water and served as normal control (CRL). The 2nd was intoxicated orally with carbon tetrachloride at a dose of $1.5 \mathrm{~mL} / \mathrm{kg}$ each 72 $\mathrm{h}$ (CCl4 group) for a period of 15 days. 2 other groups were intoxicated as $\mathrm{CCl} 4$ group and treated once daily by aqueous extract of Opuntiaficusindica $L$. at doses of $2 \mathrm{~mL} / \mathrm{kg}$ or $5 \mathrm{~mL} / \mathrm{kg}$ respectively (OFI1 and OFI2 groups). The results showed a significant elevation of Aspartate Amino Transferase (AST) (ANOVA, $\mathrm{p}<0.001$ ) and Alanine Amino Transferase (ALT) (ANOVA, $p<0.05$ ) in CCl4 group compared to control. Treatment of rats with cactus aqueous extract at $2 \mathrm{~mL} / \mathrm{kg}$ has resulted in significant reduction of AST (ANOVA, $\mathrm{p}<0.001$ ) compared to $\mathrm{CCl} 4$ group. In OFI2 group, AST and ALT were increased but non significantly compared to $\mathrm{CCl} 4$ group. The other tested parameters (Urea, creatinine and uric acid) have not recordered significant changes between all groups. The study concluded that Opuntiaficus-indica L. aqueous extract may exert hepatoprotective effect at $2 \mathrm{~mL} / \mathrm{kg}$ against CCl4-induced toxicity at least by decreasing AST enzyme activity.
\end{abstract}

Keywords: Opuntiaficus-Indica L., Aqueous Extract, CCl4, Hepatoprotective Effect

\section{Introduction}

Liver is the vital organ of metabolism and excretion. About 20000 deaths found every year were due to liver disorders. In addition, hepatocellular carcinoma is one of the ten most common tumors in the world with over 250000 new cases each year (Gupta and Misra, 2006). In spite of tremendous strides in modern medicine, there are hardly any drugs that stimulate liver function, offering protection to the liver from damage and helping regeneration of hepatic cells (Goyal and Sharma, 2012). Consecutively, several scientific studies have focused medicinal plants used in the different traditional systems, in the hope to find more potent drugs with minimum adverse effects.

Opuntia ficus-indica L. is a tropical or subtropical plant belonging to the Cactaceae family and is mainly used for fruit production (De Cortázar and Nobel, 1992).
It can be used also as a vegetable forage resource for livestock feed in arid and semiarid lands during periods of drought and shortage of herbaceous plants (Felker et al., 2006). In the majority of scientific medicinal researches involves the leaves (cladodes) rather than the fruit (El-Kossori et al., 1998). The cladodes are utilized, in traditional medicine, for the management of ulcers, wounds, rheumatic pain and fatigue. Experimental studies showed that cactus pear could reduce glucose and cholesterol levels in human blood (Frati et al., 1990; Stintzing et al., 2001). Chemopreventive effect on oxidative stress and genotoxicity was also recently investigated (Brahmi et al., 2011a). The chemical composition of cactus cladodes has been investigated in various studies. It is characterized by a high value of water (85-92\%), $4-6 \%$ of carbohydrates, $1 \%$ proteins, $0.2 \%$ fats, minerals $(1 \%)$, vitamin $\mathrm{C}(12.7 \mathrm{mg} / 100 \mathrm{~g})$ and $\beta$-carotene 


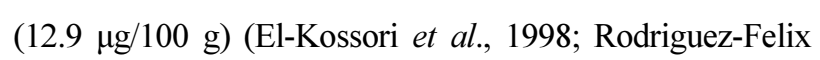
and Cantwell, 1988).

The aim of the present study is to evaluate the possible hepatoprotective effect of aqueous extract from cactus cladodes against carbon tetrachloride.

\section{Materials and Methods}

\section{Animals}

The study was conducted on 24 male Wistar rats (180-230 g weight). The animals were randomly divided on 4 groups of 6 each and were kept in standard cages for an acclimation period of 15 days with laboratory conditions. Food and water were provided adlibitum and a temperature of $22 \pm 2^{\circ} \mathrm{C}$ with a $12 / 12 \mathrm{~h}$ light/dark cycle were maintained.

\section{Tested Drugs}

Cladodes of Opuntia ficus-indica were collected in the region of Tamalous (East of Algeria) and the aqueous extract was prepared each 4 days.

$\mathrm{CCl} 4$ and ether were obtained from Faculty of Natural Sciences and Life of Constantine University.

\section{Experimental Protocol}

Four groups were formed, one control and 3 experimental lots, as follows:

- Group I: Normal control (CRL), received $2 \mathrm{~mL}$ of distilled water orally for 15 consecutive days

- Group II or CCl4: These rats were gaved every 3 days by $\mathrm{CCl} 4$ at a dose of $1.5 \mathrm{~mL} / \mathrm{kg}$ for 15 days

- Group III or OFI1: These rats received daily 2 $\mathrm{mL} / \mathrm{kg}$ of Opuntia ficus-indica aqueous extract and carbon tetrachloride $(\mathrm{CCl} 4)$ every 3 days at a dose of $1.5 \mathrm{~mL} / \mathrm{kg}$ for 15 days via oral route

- Group IV or OFI2: These animals received daily oral dose of $5 \mathrm{~mL} / \mathrm{kg}$ of Opuntia ficus-indica aqueous extract and CCl4 every 3 days at a dose of $1.5 \mathrm{~mL} / \mathrm{kg}$ for 15 days

The administration of $\mathrm{CCl} 4$ was performed $60 \mathrm{~min}$ after oral gavage of rats with the aqueous extract of Opuntia ficus-indica. All animals were given using a stomach tube. The experimental procedures involving the handling and treatment of animals were approved by the ethical committee of the institute of veterinary sciences, University of Constantine 1, Algeria.

\section{Biochemical Analysis}

All survived rats until 15th day were anesthetized on the following day with ether and blood samples were collected by cardiac puncture into heparinized tubes and centrifuged at $3000 \mathrm{rpm}$ for $10 \mathrm{~min}$ to collect sera. The biochemical analysis was performed in Biochemistry Laboratory (Polyclinic of Ain Smara, Constantine) including: ALT, AST, creatinine, urea and uric acid.

\section{Statistical Analysis}

All results were expressed as mean with variance. Data were analyzed using one-way ANOVA. The differences between groups were considered significant at $\mathrm{p}<0.05$.

\section{Results}

The results recorded in Table 1 and Figs. 1 and 2 showed a significant elevation of $\operatorname{ALT}(p<0.05)$ and AST $(p<0.001)$ enzymes in Group II due to $\mathrm{CCl} 4$ application compared with normal animals with no alliteration of other measured parameters. The administration of Opuntia ficus-indica at a dose of 2 $\mathrm{mL} / \mathrm{kg}$ has resulted in a significant reduction of AST $(p<0.001)$ in OFI1 group when compared to $\mathrm{CCl} 4$ group with no significant impact on the other tested parameters Figs. 3-5. However, the application of the aqueous extract at a dose of $5 \mathrm{~mL} / \mathrm{kg}$ has accentuated the elevation of AST and ALT but nonsignificantly in the $\mathrm{OFI} 2$ group compared to $\mathrm{CCl} 4$ group.

Table 1. Biochemical parameters of the different rat groups

\begin{tabular}{|c|c|c|c|c|c|c|c|c|c|c|}
\hline & \multicolumn{2}{|c|}{ AST (IU/L) } & \multicolumn{2}{|c|}{ ALT (IU/L) } & \multicolumn{2}{|c|}{ Urea $(\mathrm{mg} / \mathrm{L})$} & \multicolumn{2}{|c|}{ Creatinin $(\mathrm{mg} / \mathrm{L})$} & \multicolumn{2}{|c|}{ Uric Acid (mg/L) } \\
\hline & $\mathrm{Mn}$ & Var. & $\mathrm{Mn}$ & Var. & $\mathrm{Mn}$ & Var. & $\mathrm{Mn}$ & Var. & $\mathrm{Mn}$ & Var. \\
\hline CRL & 74.0 & 28.00 & 45.66 & 12.33 & 0.25 & 0.0004 & 6.25 & 10.91 & 16.66 & 25.33 \\
\hline $\mathrm{CCl} 4$ & 250.33 & 960.33 & 59.33 & 32.33 & 0.19 & 0.0015 & 6.40 & 3.80 & 10.20 & 8.20 \\
\hline OFI1 & 116.00 & 15.33 & 60.50 & 387.00 & 0.20 & 0.0004 & 5.50 & 3.60 & 14.25 & 231.58 \\
\hline OFI2 & 187.25 & 1294.25 & 144.00 & 12474.60 & 0.20 & 0.0026 & 5.50 & 3.00 & 22.00 & 247.30 \\
\hline \multicolumn{11}{|l|}{ Statistical data } \\
\hline CCl4 Vs CRL & $\mathrm{p}<0.001$ & & $\mathrm{p}<0.05$ & & NS & & NS & & NS & \\
\hline OFI1 Vs CCl4 & $\mathrm{p}<0.001$ & & NS & & NS & & NS & & NS & \\
\hline OFI2 Vs CCl4 & NS & & NS & & NS & & NS & & NS & \\
\hline OFI1 Vs OFI2 & NS & & NS & & NS & & NS & & NS & \\
\hline
\end{tabular}

Mn: Mean, Var.: Variance; NS: Nonsignificant ( $p>0.05)$ 


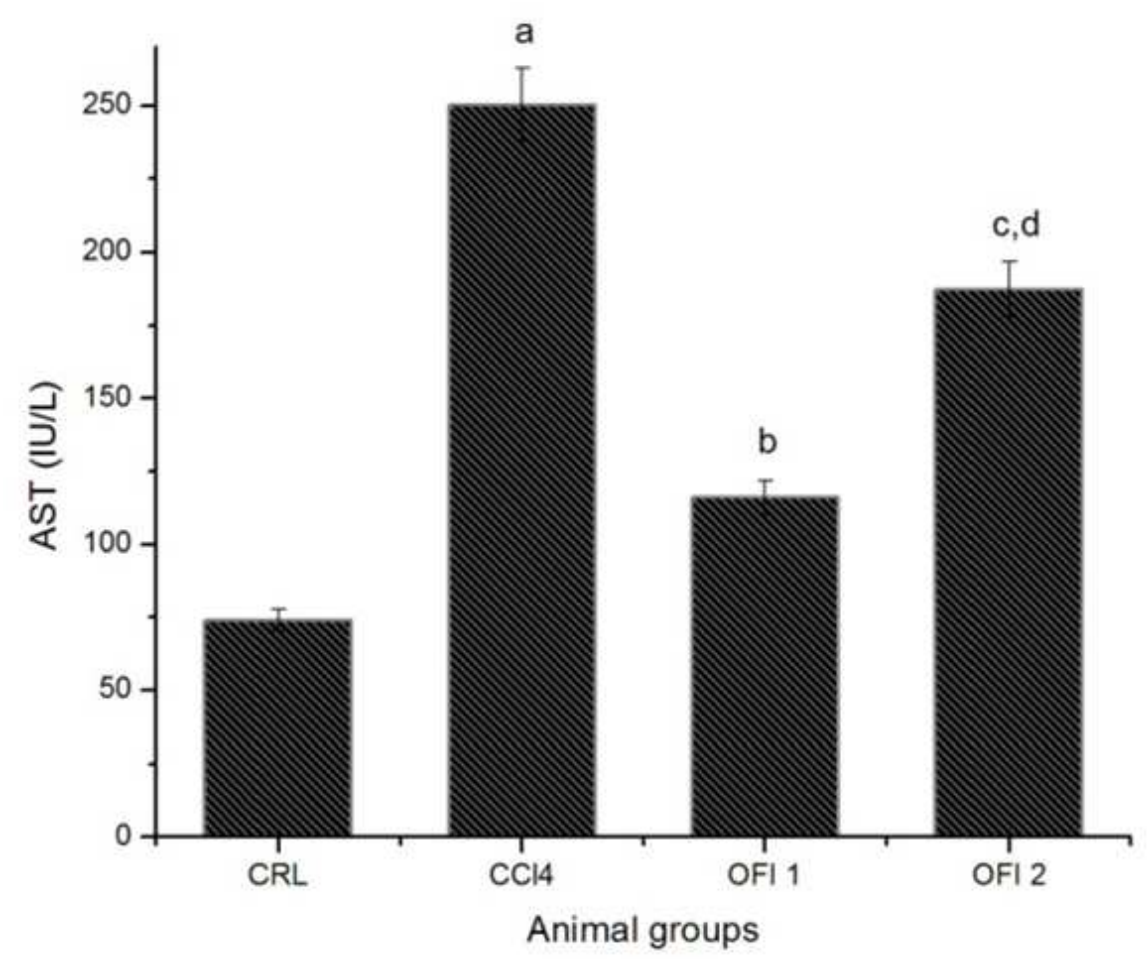

Fig. 1. AST variations in the different rat groups. CRL: normal control, CCl4: Carbontetrachloride intoxicated group, OFI1: Opuntia Ficus-Indica treated rats $(2 \mathrm{~mL} / \mathrm{kg})$, OFI2: Opuntia ficus-indica treated rats $(5 \mathrm{~mL} / \mathrm{kg}), \mathrm{NS}$ : nonsignificant, a: CCl4 Vs CRL ( $<<0.001)$, b: OFI1 Vs CCl4 (p<0.001), c: OFI2 Vs CCl4 (NS), d: OFI1 Vs OFI2 (NS)

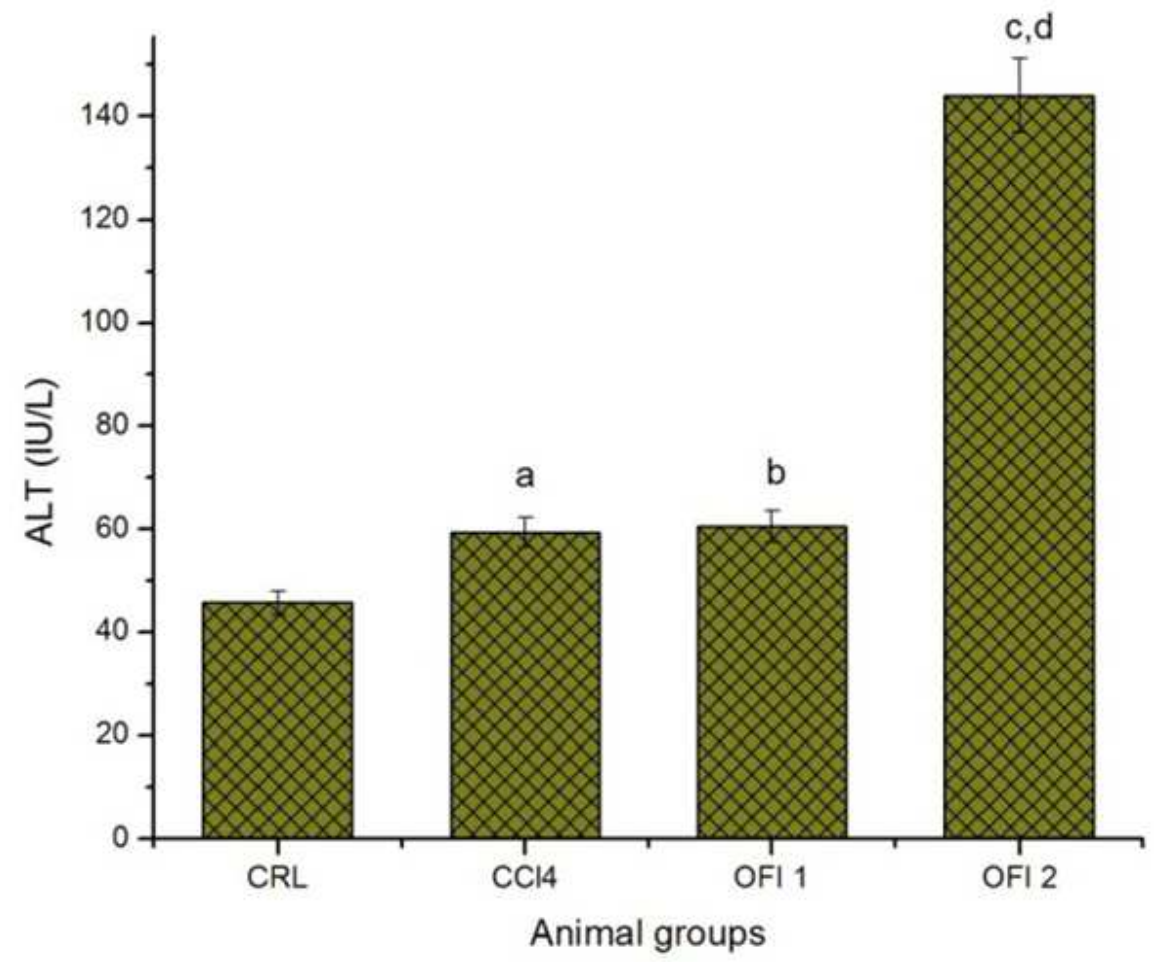

Fig. 2. ALT variations in the different rat groups. CRL: Normal control, CCl4: Carbontetrachloride intoxicated group, OFI1: Opuntia ficus-indica treated rats $(2 \mathrm{~mL} / \mathrm{kg})$, OFI2: Opuntia ficus-indica treated rats $(5 \mathrm{~mL} / \mathrm{kg})$, NS: Nonsignificant, a: CCl4 Vs CRL (p<0.05), b: OFI1 Vs CCl4 (NS), c: OFI2 Vs CCl4 (NS), d: OFI1 Vs OFI2 (NS) 


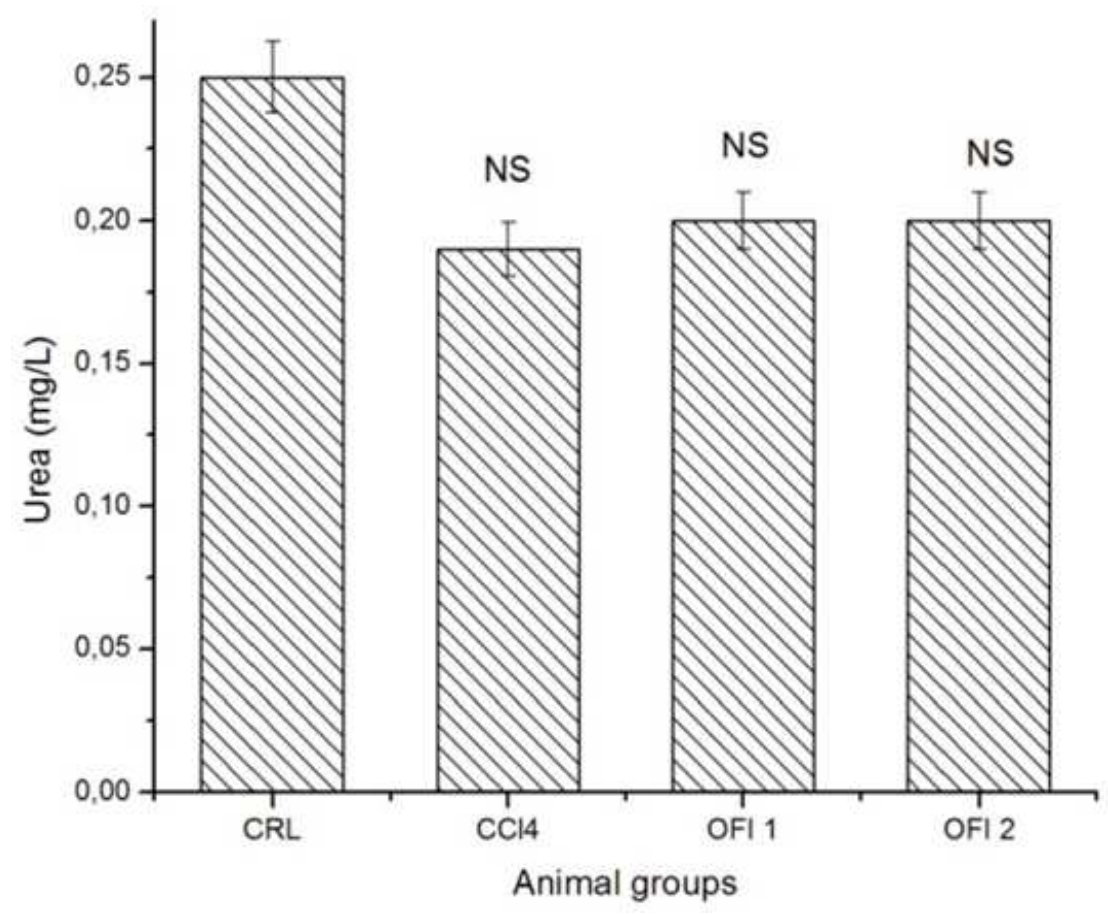

Fig. 3. Values of urea in the control and treated groups. CRL: Normal control, CCl4: Carbontetrachloride intoxicated group, OFI1: Opuntia ficus-indica treated rats $(2 \mathrm{~mL} / \mathrm{kg})$, OFI2: Opuntia ficus-indica treated rats $(5 \mathrm{~mL} / \mathrm{kg})$, NS: Nonsignificant difference between all groups

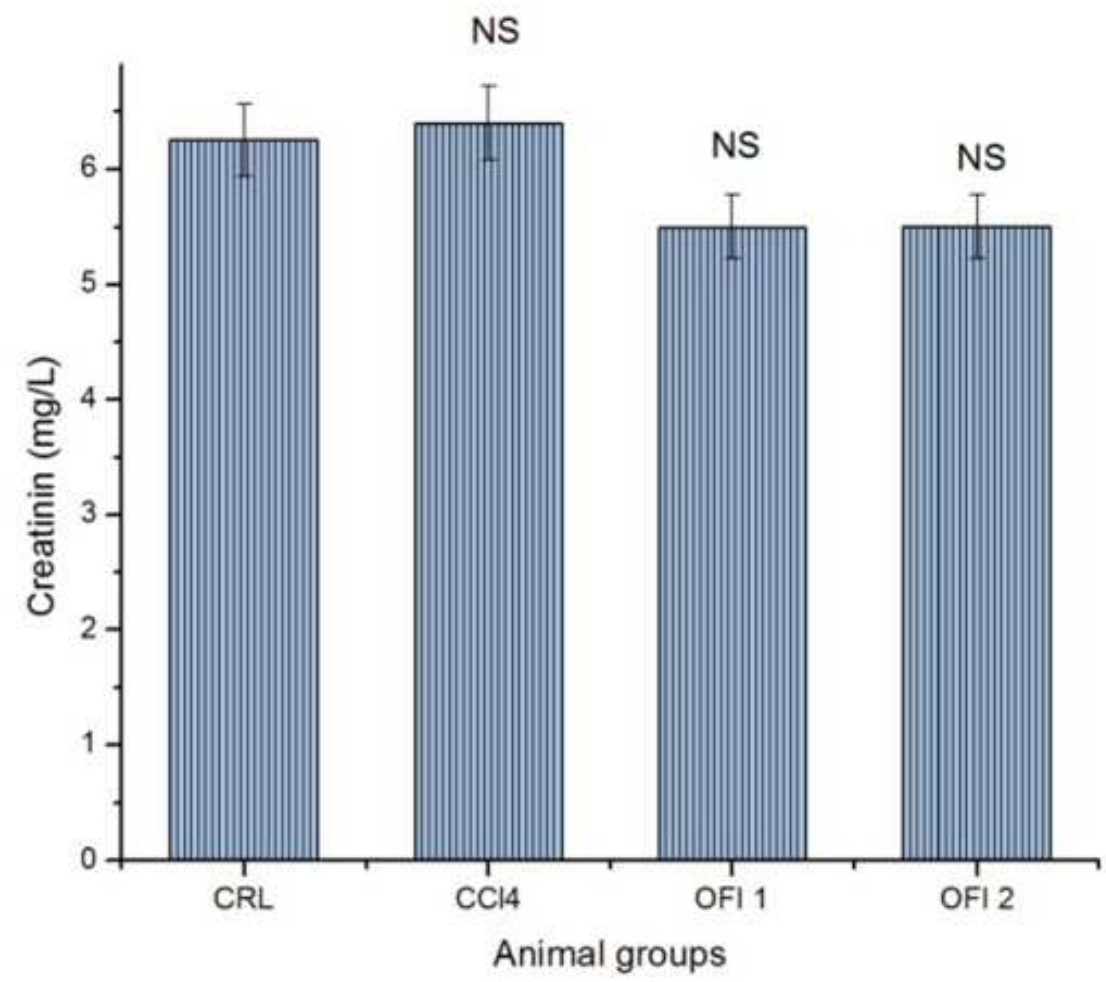

Fig. 4. Values of creatinine in the control and treated groups. CRL: Normal control, CCl4: Carbontetrachloride intoxicated group, OFI1: Opuntia ficus-indica treated rats $(2 \mathrm{~mL} / \mathrm{kg})$, OFI2: Opuntia ficus-indica treated rats $(5 \mathrm{~mL} / \mathrm{kg})$, NS: Nonsignificant difference between all groups 


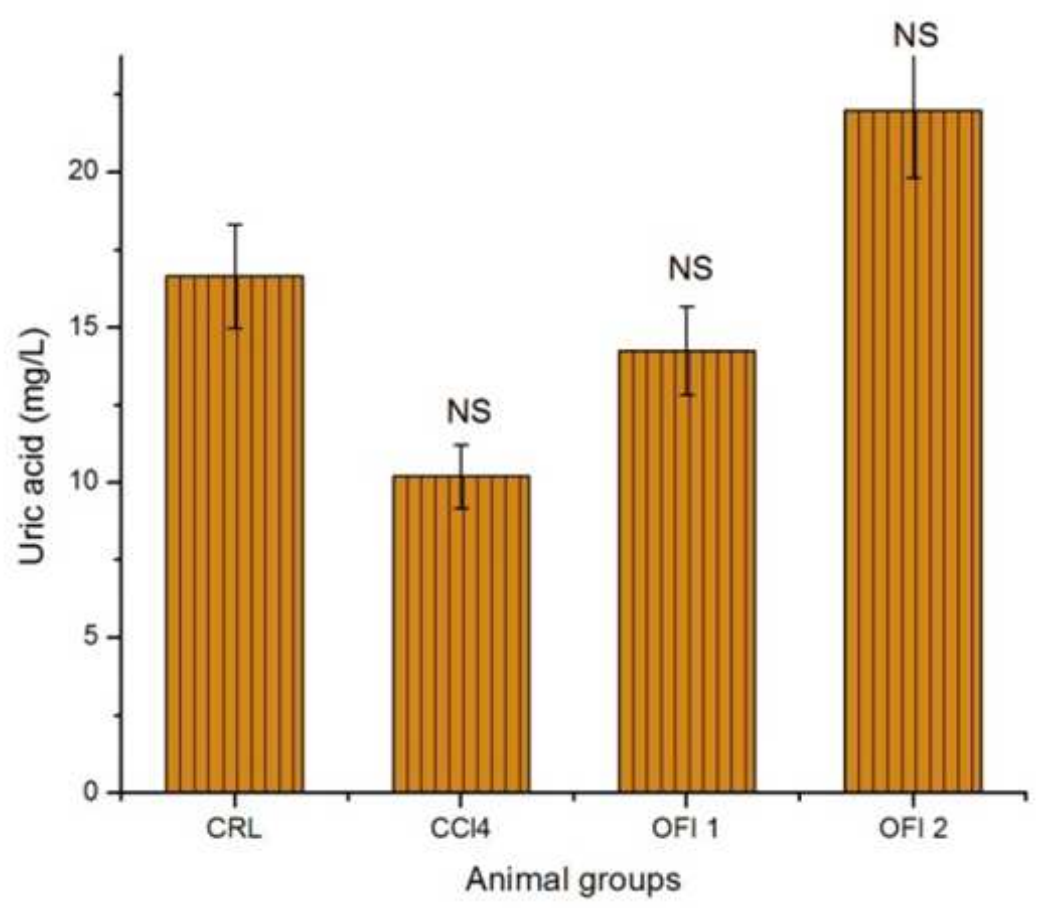

Fig. 5. Values of uric acid in the control and treated groups. CRL: Normal control, CCl4: Carbontetrachloride intoxicated group, OFI1: Opuntia Ficus-Indica treated rats $(2 \mathrm{~mL} / \mathrm{kg})$, OFI2: Opuntia ficus-indica treated rats $(5 \mathrm{~mL} / \mathrm{kg})$, NS: Nonsignificant difference between all groups

\section{Discussion}

Carbon tetrachloride is a well documented hepatotoxic drug used to induce hepatic cirrhosis model for scientific research (Gutiérrez and Solís, 2009; Karandikar et al., 1963; Recknagel, 1983). In the present study, we have applied this toxic product via oral route each 3 days for a period of 15 days to ovoid a high rate of mortality. A study of Jang et al. (2008) has compared some experimental protocols to induce liver cirrhosis in mice and rats via intra peritoneal and oral routes using 3 hepatotoxic products. They have shown that livers from animals administered $\mathrm{CCl} 4$ orally twice a week for 10 weeks was the most effective to achieve sufficient fibrosis and greatest reproducibility with acceptable animal survival.

In the present study, the dose of $2 \mathrm{~mL} / \mathrm{kg}$ of cactus aqueous extract has shown a hepatoprotective effect in term of AST decrease. However, the dose of $5 \mathrm{~mL} / \mathrm{kg}$ has accentuated the hepatic lesions which suggest that this dose is very high and may be toxic for tested animals. In a review of Feugang et al. (2006), were investigated the phytochemical composition and the medicinal uses of cactus. This vegetable has shown anti cancer, anti viral, anti diabetic (type 2 diabetes), anti hyperlipidemic and anti hypercholesterolemic effects, anti oxidant properties, anti-inflammatory activity and hepatoproptective effect against $\mathrm{CCl} 4$-induced hepato- toxicity in rats. In a study of Brahmi et al. (2011b) conducted on mice, cactus cladode extract has proven effective activity in the protection against benzo $(\alpha)$ pyrene which is a widespread environmental genotoxin classified as probably carcinogenic in human inducing liver injury. A double-lind, placebo controlled, crossover trial of Wiese et al. (2004), conducted on 64 healthy volunteers, has concluded that Opuntia ficus-indica extract has a moderate effect reducing hangover symptoms, apparently by inhibiting the production of inflammatory mediators. Finally, a study of Ncibi et al. (2008) has shown that cactus stem extract protects the liver and decrease the toxicity induced by chlorpyrifos (organophosphorous pesticide).

\section{Conclusion}

In view of the present results, it may be concluded that Opuntia ficus-indica aqueous extract at a dose of 2 $\mathrm{mL} / \mathrm{kg}$ exerted a hepatoprotective effect against carbon tetrachloride-induced toxicity in rats at least by decreasing AST activity.

\section{Acknowledgment}

We wish to thank all the staff of Biochemistry Laboratory (Ain Smara Polyclinic, Constantine) for their expert technical assistance. 


\section{Funding Information}

This study was supported by a CNEPRU research project (I00920130067).

\section{Author's Contributions}

Zouhir Djerrou: Designed the research plan and organized the study, participated in all experiments, coordinated the data-analysis and has drafted the article.

Zineb Maameri: Participated in all experiments and data analysis.

Sihem Halmi: Participated in all experiments and acquisition of data.

Hadria Djaalab and Foulla Riachi: Participated in all experiments.

Loubna Benmaiza: Participated in data analysis.

Youcef Hamdipacha: Participated in analysis and interpretation of data.

\section{Conflict of Interest}

The authors have no conflict of interest to declare.

\section{References}

Brahmi, D., C. Bouaziz, Y. Ayed, H. Ben Mansour and L. Zourgui et al., 2011a. Chemopreventive effect of cactus Opuntia ficus indica on oxidative stress and genotoxicity of aflatoxin B1. Nutr. Metabolism, 8: 1-16. DOI: $10.1186 / 1743-7075-8-73$

Brahmi, D., Y. Ayed, C. Bouaziz, L. Zourgui and W. Hassen et al., 2011. Hepatoprotective effect of cactus extract against carcinogenicity of benzo (a) pyrene on liver of Balb/C mice. J. Med. Plants Res., 5: 4627-4639.

De Cortázar, V.G. and P.S. Nobel, 1992. Biomass and fruit production for the prickly pear cactus, Opuntia ficus-indica. J. Am. Society Horticultural Sci., 117: 558-562.

El-Kossori, R.L., C. Villaume, E. El-Boustani, Y. Sauvaire and L. Méjean, 1998. Composition of pulp, skin and seeds of prickly pears fruit (Opuntia ficus indica sp.). Plant Foods Hum. Nutr., 52: 263-270. DOI: $10.1023 / \mathrm{A}: 1008000232406$

Felker, P., A. Paterson and M. Jenderek, 2006. Forage Potential of Opuntia Clones Maintained by the USDA, National Plant Germplasm System (NPGS) Collection. Crop Sci., 46: 2161-2168. DOI: $10.2135 /$ cropsci2006.02.0081

Feugang, J., P. Konarski, D. Zou, F. Stintzing and C. Zou, 2006. Nutritional and medicinal use of Cactus pear (Opuntia spp.) cladodes and fruits. Frontiers Biosci., 11: 2574-2589. DOI: 10.2741/1992
Frati, A.C., E. Jiménez and C.R. Ariza, 1990. Hypoglycemic effect of Opuntia ficus indica in non insulin dependent diabetes mellitus patients. Phytother. Res., 4: 195-197. DOI: $10.1002 /$ ptr.2650040507

Goyal, R. and P.L. Sharma, 2012. Possible mechanism of Plumbago zeylanica in prevention of hepatic dammage in wistar rat. Am. J. Pharmacol. Toxicol., 7: 101-108. DOI: 10.3844/ajptsp.2012.101.108

Gupta, A.K. and N. Misra, 2006. Hepatoprotective activity of aqueous ethanolic extract of chamomile capitula in paracetamol intoxicated albino rats. Am. J. Pharmacol. Toxicol., 1: 17-20. DOI: 10.3844/ajptsp.2006.17.20

Gutiérrez, R.M.P. and R.V. Solís, 2009. Hepatoprotective and inhibition of oxidative stress in liver of prostechea michuacana. Rec. Nat. Prod., 3: 46-51.

Jang, J.H., K.J. Kang, Y.H. Kim, Y.N. Kang and I.S. Lee, 2008. Reevaluation of experimental model of hepatic fibrosis induced by hepatotoxic drugs: An easy, applicable and reproducible model. Trans. Proceed., 40: 2700-2703. DOI: 10.1016/j.transproceed.2008.07.040

Karandikar, S.M., G.V. Joglekar, G.K. Chitale and J.H. Balwani, 1963. Protection by indigenous drugs against hepatotoxic effects of carbon tetrachloride-a long term study. Acta Pharmacol. Et. Toxicol., 20: 274-280. DOI: $10.1111 / j .1600-0773.1963 . t b 01745 . x$

Ncibi, S., M. Ben Othman, A. Akacha, M.N. Krifi and L. Zourgui, 2008. Opuntia ficus indica extract protects against chlorpyrifos-induced damage on mice liver. Food Chem. Toxicol., 46: 797-802. DOI: $10.3748 /$ wjg.v20.i40.14787

Recknagel, R.O., 1983. A new direction in the study of carbon tetrachloride hepatotoxicity. Life Sci., 33: 401-408. DOI: 10.1016/0024-3205(83)90787-7

Rodriguez-Felix, A. and M. Cantwell, 1998. Developmental changes in composition and quality of prickly pear cactus cladodes (nopalitos). Plant Foods Hum Nutr., 38: 83-93. DOI: $10.1007 / \mathrm{BF} 01092314$

Stintzing, F.C., A. Schieber and R. Carle, 2001. Phytochemical and nutritional significance of cactus pear. Eur. Food Res. Technol., 212: 396-407. DOI: $10.1007 / \mathrm{s} 002170000219$

Wiese, J., M.P. Steve, C.O. Michelle and G.S. Michael, 2004. Effect of Opuntia ficus indica on symptoms of the alcohol hangover. Arch. Int. Med., 164: 1334-1340.

DOI: 10.1001/archinte.164.12.1334 